\title{
Nivel Plasmático de Tamoxifeno e Resposta Tumoral de Pacientes com Câncer Avançado de Mama
}

\author{
Autor: Ângelo do Carmo Silva Matthes \\ Orientador: Prof.Dr. Sérgio Bighetti
}

Tese de Doutorado apresentada à Faculdade de Medicina de Ribeirão Preto da Universidade de São Paulo - Área de concentração: Tocoginecologia, em 13/02/99

O principal objetivo deste trabalho foi verificar se o nivel plasmático de citrato de tamoxifeno de pacientes com carcinoma avançado de mama em tratamento neoadjuvante, interfere na resposta tumoral. As pacientes receberam diariamente $20 \mathrm{mg}$ de citrato de tamoxifeno e após 3 meses, verificou-se uma resposta objetiva em $37 \%$ das pacientes, constituindo um grupo de 10 pacientes que responderam ao tratamento e ausência de resposta em $63 \%$, constituindo outro grupo de 17 pacientes, que não respondeu. A distribuição de freqüência de pacientes com nivel plasmático inferior e superior a $182,60 \mathrm{ng} / \mathrm{ml}$ foi significante pelo teste exato de Fisher ( $\mathrm{p}<0,0011)$. A resposta tumoral também foi associada com o estádio da doença que não mostrou significância entre os grupos; com o tipo histológico também não foi significante, sendo o carcinoma ductal infiltrante moderadamente diferenciado o mais comum; com os fatores prognósticos tumorais, também não encontramos diferenças significantes, porém para receptores de estrogênios, verifica-se que para o grupo que respondeu ao tratamento, há significância $(\mathrm{p}<0,0007)$ quando se compara antes e após o tratamento, o mesmo ocorrendo para o grupo que não respondeu $(\mathrm{p}<0,0002)$, não havendo significância entre os grupos. Todas as pacientes que responderam ao tratamento eram receptor estrogênico positivas (ER+). A associação da resposta tumoral com o perfil hormonal não mostrou significância entre os grupos. O grupo que não respondeu ao tratamento teve maior taxa de mortalidade e o tempo médio de seguimento foi de 19 meses para o grupo que respondeu e 21 para o que não respondeu.

Palavras-chave: Câncer de mama. Resposta tumoral. Receptores. Tamoxifeno.

\section{Efeito de uma Ação Educativa sobre a Conduta dos Profissionais de Saúde da Rede de Atenção Primária em Relação às Doenças de Transmissão Sexual}

\author{
Autora: Arlete Maria Dos Santos Fernandes \\ Orientador: Prof. Dr. Luiz Guillermo Bahamondes
}

Tese de Doutorado apresentada ao Curso de Pós-Graduação em Medicina, área de Tocoginecologia, da Faculdade de Ciências Médicas da Universidade Estadual de Campinas - UNICAMP, em 22/02/1999.

Resumo: Estudamos o efeito de uma ação educativa voltada aos profissionais de saúde que prestam atenção gineco-obstétrica em seis Centros de Saúde da rede municipal de Campinas, sobre suas opiniões e atitudes com relação às doenças sexualmente transmissiveis (DST), bem como determinamos conhecimentos, atitudes e práticas de prevenção da população de mulheres atendida. Uma amostra de 249 mulheres, 33 médicos e enfermeiras foram entrevistados, e 3625 prontuários foram levantados para determinar a freqüência de diagnósticos relacionados às DST. Os resultados mostraram que, apesar de $25 \%$ dos diagnósticos realizados estarem relacionados às DST, a intervenção realizada foi ineficaz para promover mudança significativa no comportamento dos profissionais. Entretanto, houve diminuição significativa nos diagnósticos de tricomoníase, monilíase e leucorréia com sinais inflamatórios e aumento nos diagnósticos das DST virais. Apesar das mulheres demonstrarem confiança no médico, $87,6 \%$ citaram a televisão como fonte de informação. O uso do condom foi referido por $10 \%$ delas e $8 \%$ faziam uso freqüente. Concluímos que as mulheres não se sentem vulneráveis para contrair DST/AIDS, logo, não optam pelo uso do condom. Quando o utilizam, a intenção é a contracepção. Devemos implementar a adoção do diálogo informativo a respeito das DST/AIDS, durante a graduação, para que os profissionais possam identificar as mulheres expostas através da história clínica, desenvolvam a habilidade em falar aberta e claramente acerca dos comportamentos de risco e estejam preparados para esclarecer sobre complicações futuras das DST e as medidas de prevenção possiveis. Devemos inovar a forma e a qualidade das informações para maior aderência da população às práticas do comportamento sexual seguro.

Palavras-chave: Doenças sexualmente transmissivveis. Orientação sexual. Vulvovaginite. Contracepção. Condom. 